\title{
Ceremonial y cambios en el protocolo tras un año de reinado
}

\section{Ceremonial and protocol changes after one year of monarchy}

\author{
Dolores del Mar Sánchez González ${ }^{1}$ \\ Manuel Casado Trigo ${ }^{2}$ \\ Universidad Nacional de Educación a Distancia \\ mdmsanchez@der.uned.es \\ manuelcasadobisemol@gmail.com
}

Recepción: 01/06/2015 Revisión: 01/06/2015 Aceptación: 02/06/2015 Publicación: 07/06/2015

http:// (página web de inclusión del artículo)

\section{Resumen}

Análisis de la ceremonia de jura y proclamación de Felipe VI, y cambios a nivel de protocolo a partir del inicio del nuevo reinado: títulos, simbología real, composición de la nueva Familia Real, modificaciones a nivel de tratamientos y precedencias.

Palabras clave: ceremonia, jura, protocolo, Felipe IV, proclamación.

Abstract

Analysis of the swearing-in ceremony and proclamation of Philip $\mathrm{VI}$, and protocol-level changes from the beginning of the new reign: titles, Real symbology, composition of the new Royal Family, modifications at treatments and precedence.

Keywords: ceremony, swearing-in, protocol, Felipe VI, proclamation.

\section{Sumario}

1. Introducción

2. Desarrollo

3. Conclusiones

4. Bibliografía

\footnotetext{
${ }^{1}$ Profesora Titular de la Facultad de Derecho y Coordinadora del Master Universitario en Protocolo de la UNED.

2 Doctor en Derecho. Sociedad de Estudios Institucionales. GIHPJ-P UNED
} 


\section{Summary}

1. Introduction

2. Exposition

3. Conclusions

4. Bibliography

\section{INTRODUCCIÓN}

Para comprender la importancia del juramento en el acto de proclamación de Felipe VI, resulta esencial de una manera introductoria ofrecer una definición del concepto. En este sentido, de acuerdo con la definición que nos ofrece la Real Academia Española (RAE), hablamos de juramento (Del lat. iuramentum) como la "afirmación o negación de algo, poniendo por testigo a Dios, o en sí mismo o en sus criaturas". Destacan de esta acepción dos elementos importantes: por un lado, el hecho de afirmar o negar algo y, por otro, la mención a Dios como valedor o fedatario de dicho acto. Ello nos lleva a hablar, en primer término, del llamado juramento asertorio definiéndolo como el "juramento con que se afirma la verdad de algo presente o pasado ${ }^{33} \mathrm{y}$, por otro, de juramento promisorio que pone a la divinidad como testigo preceptivo del cumplimiento de una promesa, dejando la pena por un eventual incumplimiento sometida únicamente a la consideración de Dios. No existe, por tanto, una tipificación punitiva por incumplimiento del juramento promisorio.

En España, superada la etapa histórica del Antiguo Régimen, estas clases de juramentos protagonizarán, entre otros, el periodo de la monarquía constitucional, donde la Constitución se encuentra en la cúspide normativa y a la que el monarca se adhiere como un signo de limitación de sus antiguos poderes absolutos. No obstante, esa forma de adhesión a la Constitución mediante la fórmula del juramento será diferente según se trate de Constituciones más moderadas o más progresistas. En el caso de las primeras, el monarca aceptaba autolimitarse, era un pacto entre las Cortes y el Rey; sin embargo, para las Constituciones más progresistas, donde la premisa fundamental era el reconocimiento de la soberanía nacional, el juramento real constituía el sometimiento del Rey a dicha soberanía.

\footnotetext{
${ }^{3}$ Definición de la RAE.
} 
Nuestra vigente Constitución de 1978 se refiere, en su artículo 61.1, al juramento cuando dice: «El Rey, al ser proclamado ante las Cortes Generales, prestará juramento de desempeñar fielmente sus funciones, guardar y hacer guardar la Constitución y las leyes y hacer respetar los derechos de los ciudadanos y de las Comunidades Autónomas». La doctrina discrepa acerca de los efectos constitutivos o meramente declarativos de esta fórmula recogida en la Carta Magna. Así, frente a las tesis de López Guerra, que argumentaba que con este juramento no se quería sino reafirmar el carácter parlamentario de la monarquía ya expresado en el artículo $1.3 C E^{4}$, coadyuvado por el criterio de Torres del Moral que lo privaba también de efectos constitutivos, relegándolo a mantener un sentido simbólico o de compromiso con la Constitución ${ }^{5}$, será del propio texto contenido en el artículo 61.1 de la Carta Magna del que se venga a confirmar el sometimiento del Rey a la Constitución y a las leyes, impidiéndole al Rey ejercer legítimamente sus funciones sin cumplir previamente este trámite de juramento.

Por otro lado, a diferencia de los textos constitucionales decimonónicos, no contiene la vigente Constitución una fórmula ritual de juramento, limitándose a decir el artículo 61.1 que el Rey "al ser proclamado ante las Cortes Generales, prestará juramento...» 6 . Igualmente, y tal como analizaremos a continuación con el desarrollo del acto de proclamación, queda descartada cualquier ceremonia religiosa vinculada a este acto, suponiendo, hoy día, más bien un compromiso personal, a diferencia del que antaño se ponía bajo la sanción divina como garantía de su intensidad? ${ }^{7}$.

\footnotetext{
${ }^{4}$ LÓPEZ GUERRA, L., "Artículo 61. Juramento" en Comentario a la Constitución Española de 1978, dir. O. Alzaga Villaamil, t. V (arts. 56 a 65), Edersa-CC.GG, Madrid, 1996.

${ }^{5}$ TORRES Del MORAL, A., El Príncipe de Asturias. Su estatuto jurídico. Congreso de los Diputados, Madrid, 1997, pág. 89.

${ }^{6}$ Esta cuestión, aún no resuelta hoy en día, quedaría relegada a su regulación por el Reglamento de las Cortes Generales previsto en el artículo 72.2 CE: "Las Cámaras eligen sus respectivos Presidentes y los demás miembros de sus Mesas. Las sesiones conjuntas serán presididas por el Presidente del Congreso y se regirán por un Reglamento de las Cortes Generales aprobado por mayoría absoluta de cada Cámara".

${ }^{7}$ HERRERO DE MIÑÓN, M. El juramento regio. Reflexiones en torno al artículo 61.1 CE. Revista de Derecho Político, 2001, pág. 13.
} 


\section{DESARROLLO}

Este estudio se circunscribe al estudio de la jura y proclamación de Felipe VI, de las notas y conceptos esenciales y comparación con antecedentes históricos y el marco normativo vigente en cada momento.

El marco teórico ha sido en parte estudiado por diferentes autores, pero con carácter general (no para estas ceremonias concretas) y sin llegar a plasmarse en resultados o conclusiones como las propuestas en este trabajo.

Se parte de la teoría de que los cambios en el ceremonial se deben a necesidades de comunicación determinadas y vienen a ser un instrumento que refleja materialmente el peso del poder efectivo de los protagonistas, pudiendo este hecho incluso llegar a preponderar sobre la normativa aplicable en un Estado de Derecho.

En cuanto a la metodología, recurriendo a diferentes tipos de fuentes bibliográficas, se ha comparado el reciente acto de jura y proclamación de Felipe VI con los últimos actos de jura y proclamación en la historia española, prestando especial atención a las características de los elementos más relevantes de la ceremonia: precedencias, símbolos, fórmulas de juramento, etiqueta, rol de protagonistas, normativa... Todos estos elementos se han contrastado con la normativa aplicable y el objetivo de comunicación perseguido en cada caso.

El protocolo es, en sentido amplio, el conjunto de normas, usos y costumbres que determinan el orden de celebración de un determinado acto, cuya finalidad, en el caso del protocolo institucional, es la de transmitir la imagen del poder a los ciudadanos, mediante la utilización de una serie de técnicas y herramientas concretas. La ceremonia de jura y proclamación supone un doble juramento del Rey al Reino -la aceptación de las normas constitucionales y la estructura del Estado- y de lealtad institucional del Reino al Rey.

A nivel protocolario asistimos hace un año a una renovación incompleta del ceremonial, con presencia de ciertos elementos perturbadores. La cronemia, la proxemia y la etiqueta del acto no han sido acertadas, por alterar el mensaje que se quería transmitir. 
Como acto previo esencial, debemos mencionar la ceremonia de Sanción y Promulgación de la LO de abdicación realizada por el rey Juan Carlos I en el Salón de Columnas del Palacio Real de Madrid, a las $18 \mathrm{~h}$. del día 18 de junio de 2014. El protagonista del acto fue S. M. D. Juan Carlos I, que hizo efectiva la comunicación realizada el día 2 de junio, sancionando y promulgando la LO de abdicación, refrendada por el Presidente del Gobierno. Asistieron unos 150 invitados institucionales.

La ceremonia de sanción de la ley orgánica destacó por la presencia de los príncipes de Asturias y por la cesión del asiento del rey saliente (don Juan Carlos) al entrante (don Felipe). Consideramos que ambas cosas nunca debieron realizarse: la presencia de don Felipe por innecesaria y la cesión del asiento por respeto a las Cortes, que es a quien corresponde la proclamación del nuevo rey. Con la cesión del asiento presidencial por don Juan Carlos a don Felipe, el mensaje que se ha lanzado a la ciudadanía era que el rey saliente era quien investía, proclamaba o reconocía en ese mismo momento al rey entrante y por tanto podía hacerlo, tenía ese derecho. Fue una especie de ceremonia de proclamación pero dicha proclamación sólo podía tener lugar hoy ante las Cortes. El rey saliente se atribuyó en ese momento un poder que no tenía y redujo la importancia que las Cortes tienen como representantes de la soberanía popular al nivel de mero testigo para la ceremonia de proclamación de hoy. Este aspecto tiene especial importancia en un país en el que asistimos a un reforzamiento inusitado del poder ejecutivo en detrimento de los otros poderes del Estado y lanza un mensaje muy negativo del papel que tienen los representantes del poder legislativo como representantes últimos de la voluntad popular, sometido en este caso al poder del rey.

Dentro de los actos del 19 de junio, vimos que se dividieron los actos en dos partes: la imposición de la faja de Capitán General al ya rey Felipe VI y la Ceremonia de Jura y Proclamación del nuevo rey.

La ceremonia de imposición del fajín de Capitán general al rey programada para las 09:30 del día 19/06 se celebró en la Sala de Audiencias del Palacio de la Zarzuela, residencia personal del monarca y edificio sin tradición militar, salvo por ser la vivienda del Jefe del Estado. Además de lo incomprensible de la realización con anterioridad a la proclamación. El acto de traspaso de poderes militares, como jefe supremo de las Fuerzas Armadas, debería tener 
lugar, aceptando que sea con el ceremonial y protagonistas que se ha utilizado (también discutible, pues no tenía sentido el que compartieran asiento en representación de las instituciones del Estado, los poderes del mismo y la esposa del Presidente del Gobierno), en un momento posterior al de proclamación, que es el relevante para que el nuevo rey asuma todas sus funciones. Así por ejemplo, no se vería lógico que sancionara ninguna ley antes de su proclamación. Debemos recordar que la constitución otorga al rey la jefatura de las Fuerzas Armadas en su letra h) (sancionar las leyes es la primera) dentro del artículo 62 de la Constitución Española y tampoco se encuentra en la definición de sus funciones esenciales que realiza el artículo 56:

“El Rey es el Jefe del Estado, símbolo de su unidad y permanencia, arbitra y modera el funcionamiento regular de las instituciones, asume la más alta representación del Estado español en las relaciones internacionales, especialmente con las naciones de su comunidad histórica, y ejerce las funciones que le atribuyen expresamente la Constitución y las leyes".

Nuevamente nos encontramos con un ejercicio de funciones incorrecto, por el momento, de los protagonistas y la potestad ejercida. Las Cortes vuelven a presentarse como un poder no efectivo, sujeto a la voluntad del monarca, que traspasa los límites constitucionales. No obstante la arquitectura realizada para dar visibilidad al acto muestra un resultado anacrónico con el mensaje el mensaje en sí y la configuración real de la Jefatura del Estado en nuestro país. ¿Es la Jefatura del Estado un órgano que depende del poder ejecutivo?

El acto transmite una clara reminiscencia sobre el anterior régimen autoritario, donde el ejército jugaba un papel protagonista en la vida institucional. Al realizarse este acto con anterioridad a la proclamación y con solución de continuidad, parece ser que los organizadores veían lógico que S.M. D. Felipe acudiera a dicho acto con uniforme militar. Ni la tradición, ni la consecuente reminiscencia de la proclamación de D. Juan Carlos, jurando los principios del Movimiento, era comunicativamente el mensaje adecuado a los tiempos que corren. El mito del "rey soldado", que en su momento la política restauradora canovista ideó para Alfonso XIII, no tiene cabida alguna en nuestra actual sociedad. Se puede argumentar que se trata con esta manifestación de supeditar el ejército a la sociedad civil, pero en los tiempos que corren y con la modernización ideológica, estructural e institucional 
del ejército, este tipo de mensajes carece de sentido. Si acudimos a casos similares y recientes, ni el rey de Holanda utilizó uniforme militar ni por supuesto los presidentes de las repúblicas de Francia o Estados Unidos de América, a pesar de ser sociedades mucho más militarizadas que la española.

El acto de jura y proclamación es ceremonial laico y así se manifestó retirando el tradicional crucifijo que desde las Cortes de Cádiz -e incluso antes- se encontraba presente en la jura de cualquier autoridad, y la supresión del Te Deum, o Misa de Espíritu Santo, por aquello de la aconfesionalidad del Estado. Un paso para la renovación y, sin embargo, otro mirando al pasado plasmado en la etiqueta elegida para el acto de jura y proclamación: uniforme de gran gala del Ejército de Tierra. ¿Ceremonia laica y militar? Era inevitable la comparación de imágenes entre reinados. No se trata de que el Rey vistiera traje oscuro como un presidente de república, pero en nuestra opinión el chaqué hubiera sido la indumentaria apropiada.

Este acto solemne es un acto del pueblo representado por las Cortes en el que, paradójicamente se ha dado un protagonismo excesivo al poder ejecutivo en detrimento y deslegitimación del poder legislativo, verdadero depositario de la soberanía popular. Resulta incomprensible el excesivo papel desempeñado por el presidente del Gobierno en toda la ceremonia, que transmite la imagen de supeditación del poder legislativo al ejecutivo: ¿̇es el presidente del gobierno quien toma juramento al Rey? La estructura del acto, siguiendo precedentes similares, planteó el recibimiento en dos pasos, cuando la recepción hubiera debido realizarse a pie de coche delante de las mismas puertas del Congreso por los presidentes del Congreso y del Senado, que son los anfitriones; en segundo lugar, por una ubicación incorrecta del presidente del Gobierno que hubiera debido ocupar su puesto en el "banco azul", que es el que le corresponde; en tercer lugar, porque en el lugar donde se encontraba don Mariano Rajoy en el hemiciclo, debería haber estado el ministro de Justicia, Notario Mayor del Reino, como fedatario de lo que allí estaba aconteciendo y no el presidente de gobierno. Como nota de contraste vemos que con ocasión de la proclamación de Juan Carlos I, el Gobierno, encabezado por su presidente, don Carlos Arias Navarro, ocupaba el «banco azul». ¿Ante qué tipo de monarquía nos encontramos? Parece, a la vista de estos hechos, que el rey estuviera supeditado al poder ejecutivo. 
Sí nos parece acertado el recorrido posterior al acto, que muestra a los españoles a su nuevo Rey, y la elección del coche descapotable. Aunque sin duda repercute en la seguridad del acto, ha trasmitido con mucha fidelidad la tradición histórica de las Entradas Reales, momento en el que el rey invisible se transformaba en visible para el pueblo. Y lo mejor, la guinda: la salida de la nueva Familia Real al balcón del Palacio Real. Una imagen correctísima, medida y estudiada que pone de manifiesto los cambios para el protocolo: título, tratamiento, honores, Familia Real, orden de precedencia y simbología real. En ese último paso, el mensaje ha sido en todo momento el que se pretendía transmitir.

\section{Cronograma de los actos:}

18/06 18:00 Salón Columnas del Palacio Real

Ceremonia de Sanción y Promulgación de la LO de abdicación

\section{9/06 09:30 Sala de Audiencias}

Palacio de la Zarzuela

10:00 Zarzuela

10:30 Congreso
Imposición del fajín de Capitán General al rey Don Felipe VI

Salida de SS.MM. los Reyes Felipe y Letizia.

Recorrido en automóvil hasta Cortes Generales.

Llegada al Congreso.

Honores de los Tres Ejércitos en la Carrera de S. Jerónimo.

Saludos en la Puerta de los Leones.

Entrada al hemiciclo.

Sesión conjunta de las Cortes Generales.

Juramento y proclamación previsto en la

Constitución.

Interpretación del Himno Nacional (versión

extendida).

Discurso de S.M. El Rey.

Desfile Militar en la Puerta de Los Leones. 
11:30 Congreso

12:00 Palacio Real

13:00 Palacio Real
Salida de la Familia Real e inicio del recorrido en coche hasta el Palacio Real.

Salida de la Familia Real al balcón central de Palacio para saludar.

Recepción.

Saludo en el Salón del Trono.

En estos momentos se requiere hay, más que nunca, adaptar el protocolo a la realidad social y recordar que los jefes de protocolo están al servicio de las instituciones y no de quien ocupa el cargo en ese momento. Sería muy conveniente el recordar el papel institucional de cada uno en el Estado Social y Democrático de Derecho instaurado tras la Constitución de 1978.

Desde hace un año venimos asistiendo a modificaciones protocolarias contradictorias que en ocasiones se justifican en base a una tradición inexistente y en ocasiones se afanan en mostrarnos una monarquía que no tiene nada que ver con tiempos pasados. Centrándonos en las modificaciones relativas al protocolo, debemos comenzar con las relativas a los tratamientos. La norma aplicable es el RD 1368/1987, de 6 de noviembre sobre Títulos, Tratamientos y Honores de la Familia Real y de la Regencia, modificado por el RD 470/2014, de 13 de junio para añadir la disposición transitoria cuarta. De acuerdo con lo establecido, el titular de la Corona es S.M. el rey don Felipe VI; la reina consorte es S.M. la reina doña Letizia; la heredera de la Corona es S.A.R la Princesa de Asturias, doña Leonor y la siguiente en la línea de sucesión es S.A.R. la Infanta, doña Sofía. D. Juan Carlos conserva el título de rey (pierde el ordinal), con tratamiento de Majestad y Honores de Príncipe de Asturias (¿?), colocándose en el orden de precedencias a continuación de la Infanta doña Sofía. Dña. Sofía, conserva el título de reina, con tratamiento de Majestad y Honores de Princesa de Asturias. La solución presentada, cuanto menos es inventada, pero además no sabemos que mejora puede aportar ni a la institución de la monarquía ni a su sucesora. 
Respecto de la simbología real, las Armas del Príncipe de Asturias fueron creadas por el RD 284/2001, de 16 de marzo. Tiene pues don Felipe VI armas propias ahora modificadas, con el asesoramiento de la Real Academia de la Historia, para adaptarlas al nuevo reinado. El color del estandarte y del guion de S. M. don Felipe VI es el rojo carmesí, color típico de la monarquía española. Dicho color se incorpora también al fondo de la matrícula real de los vehículos de S.M. Se eliminan del escudo el yugo y las flechas, herencia de los Reyes Católicos y la Cruz roja de Borgoña, y cambia la corona de príncipe al timbre, por la corona de rey (8 diademas de la que son visibles sólo 5). Con este hecho Felipe VI vuelve al tradicional color de nuestra monarquía no alterado salvo por Isabel II y por D. Juan Carlos.

El RD 1368/1978, de 6 de noviembre sobre Títulos, Tratamientos y Honores de la Familia Real y de la Regencia, con la inclusión de la Disposición Transitoria cuarta realizada por el RD 470/2014 de 13 de junio y RD 2917/81 de 27 de noviembre que regula el Registro Civil de la Familia Real, determinan la composición de la Familia Real. Está formada por S.M. don Felipe VI, S.M. doña Letizia, S.A.R. doña Leonor, S.A.R. doña Sofía, Su Majestad don Juan Carlos, Su Majestad doña Sofía. Por su parte, las Infantas hermanas del Rey y sus cuñados, sus tías y sus primos forman la Familia del Rey. Una vez más el estupor nos deja atónicos pues existía un consenso en considerar que la Familia Real, componía a todos aquellos incluidos en un Registro especialmente creado al efecto, relacionado directamente con el orden de sucesión. De hecho en el acto de imposición de la Faja a D. Felipe pudimos observar cómo Dña. Helena y don Froilán, siguientes en la línea de sucesión, tenían su lugar determinado en el acto, de acuerdo con el orden de precedencias y en función de la sucesión a la Corona. Ahora tenemos a dos personas en la línea de sucesión a la Corona, que no forman parte de la Familia Real, por el efecto de la supresión apresurada de las hermanas del Rey de los actos de los actos públicos, supresión a la que en los últimos tiempos ya empezamos a asistir.

Gracias al protocolo, las ceremonias de sanción de la ley orgánica de abdicación y la de proclamación pueden ser analizadas de una manera más profunda, analizando los mensajes que deliberadamente se han querido lanzar, más allá de los discursos o los gestos.

Los mensajes protocolarios nos ofrecen una gran seguridad a la hora de su interpretación ya que sabemos que fueron estudiados y negociados cuidadosamente por las distintas jefaturas de protocolo antes de la celebración de los actos y con una finalidad comunicativa concreta. 
Poco queda a la improvisación. El protocolo es un instrumento muy útil para analizar los actos políticos como los que hemos visto ayer y hoy. La escenificación del traspaso de poder ha dejado mucho que desear, y consideramos que no ha repercutido positivamente en nueva forma de ejercer el poder, la mejora del funcionamiento de las instituciones y poderes públicos.

Dos novedades más encontramos relativos al protocolo: la supresión del crucifijo en los actos de jura de autoridades realizados en presencia de S.M., que debe ser solicitado expresamente para su colocación por la autoridad que jura el cargo -lo cual es de dudosa constitucional habida cuenta de que nadie puede ser obligado a pronunciarse sobre sus creencias y la medida es un tanto distorsionadora- y el hecho de que cuando un Jefe de Estado acude al Palacio Real, D. Felipe desciende las escaleras de Palacio para recibirle a pie de coche. Esto último ni nos parece bien ni nos parece mal, pero ¿Cuál es el mensaje que estamos proyectando? ¿estamos ante una monarquía presidencialista?.

\section{CONCLUSIONES}

Entre los resultados más destacados de la investigación podemos enumerar:

- La variación notable en aspectos esenciales de la ceremonia, como las precedencias y la permanencia de otros aspectos, como la simbología.

- La importancia dada a las precedencias como forma de representación de la detentación del poder efectivo.

- La identificación de diferencias en la fórmula de jura, elementos proxémicos, a nivel de tratamientos.

- Las teorías planteadas inicialmente se han venido a confirmar tras el estudio histórico comparativo, normativo y evolutivo de acto de jura y proclamación de Felipe VI.

- Dicho acto ha estado sujeto a diferentes cambios de ceremonial, procedencias, fórmulas, pero todos ellos se explican por las necesidades de comunicación existentes en cada momento. 
- Estas necesidades de comunicación pueden ser contrarias a la tradición o la normativa, pero el protocolo se constituye en una herramienta de manifestación del poder, una poderosa herramienta de comunicación superando ambos.

\section{BIBLIOGRAFÍA}

HERRERO DE MIÑÓN, M. (2001) El juramento regio. Reflexiones en torno al artículo 61.1 CE. Revista de Derecho Político.

LÓPEZ GUERRA, L. (1996) “Artículo 61. Juramento” en Comentario a la Constitución Española de 1978, dir. O. Alzaga Villaamil, t. V (arts. 56 a 65), Madrid, Edersa- CC.GG.

SÁNCHEZ GONZÁLEZ, D. del M. (2011) Fundamentos del Ceremonial y del Protocolo, Madrid. Síntesis.

TORRES DEL MORAL, A. (1997) El Príncipe de Asturias. Su estatuto jurídico. Madrid. Congreso de los Diputados. 